\title{
Real-time monitoring of mechanochemical formation of pharmaceutical cocrystals using synchrotron X-ray diffraction
}

Luzia S. Germann, ${ }^{a^{*}}$ Mihails Arhangelskis, ${ }^{\mathrm{b}}$ Robin Stein, ${ }^{\mathrm{b}}$ Leigh Loots, ${ }^{\mathrm{b}, \mathrm{c}}$ Cristina Mottillo, ${ }^{\mathrm{b}}$ Joseph Marrett, ${ }^{\mathrm{b}}$ Jean-Louis Do, ${ }^{\mathrm{b}}$ Nicola Casati, ${ }^{\mathrm{d}}$ Tomislav Friščić ${ }^{\mathrm{b}}$ and Robert E. Dinnebier ${ }^{\mathrm{a}}$

${ }^{a}$ Max-Planck-Institute for Solid State Research, 70569 Stuttgart, Germany. ${ }^{\mathrm{b}}$ McGill University,Montreal, Qc, Canada. ${ }^{\mathrm{c}}$ Stellenbosch University, Stellenbosch, South Africa, ${ }^{\mathrm{d}}$ Swiss Light Source, Paul Scherrer Institute, CH5232 Villigen, Switzerland Email: 1.germann@fkf.mpg.de

The synthesis of cocrystals composed of active pharmaceutical ingredients (APIs) is a rapidly growing research field, and one of the central topics of modern pharmaceutical materials science.[1] A number of different approaches have been developed to screen and synthesize such pharmaceutical cocrystals, including solution cocrystallization,[2] accelerated aging,[3] and mechanochemistry.[4] The latter has not only proven to be an extremely efficient route for cocrystal discovery, but is also a powerful method for bulk synthesis of solid phases that are metastable or even impossible to attain by other means.[5] Furthermore, mechanochemistry enables the synthesis and screening of pharmaceutical cocrystals regardless of the solubility of the individual components.[6] However, the mechanisms of mechanochemical cocrystallization remain poorly understood: the first technique for real-time, in situ monitoring of ball milling mechanochemistry was introduced very recently and applied in the evaluation of the reaction mechanisms of microporous framework formation. [5,7]

Here, we describe the results of real-time X-ray powder diffraction monitoring of mechanochemical cocrystallization using a novel, high-resolution setup at the X04SA beamline (SLS, Villigen).[8] The high data quality enabled us to conduct the first detailed analysis of the appearance of metastable polymorphs and stoichiometric variations in a library of related cocrystals. New cocrystal and polymorphic crystal structures were solved using ab initio methods and verified using complementary methods.
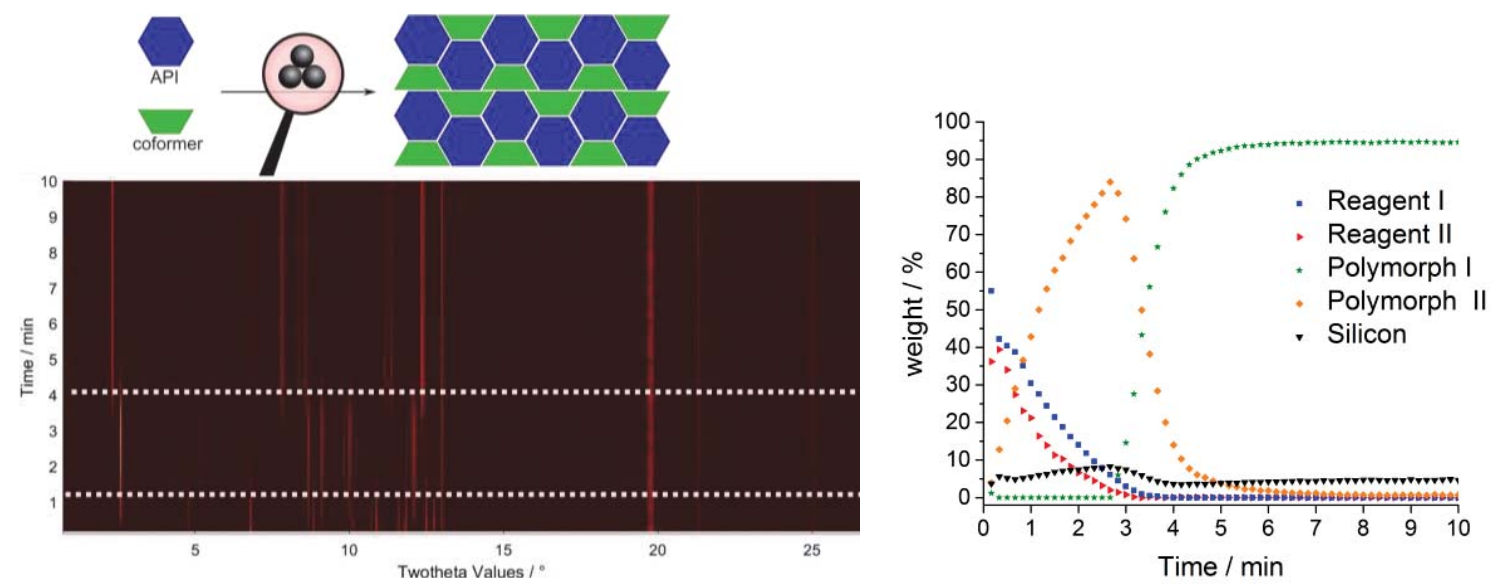

Figure 1: In situ monitoring of the formation of different cocrystal phases, measured at the X04SA beamline at SLS, Villigen.

Keywords: cocrystals, mechanochemistry, in situ X-ray powder diffraction

[1] Tan et al., Chem. Commun., 2016, 52, 7760; [2] Rodríguez-Hornedo et al., Mol. Pharm., 2006, 3(3), 362; [3] Huskić et al. Chem. Comm., 2016, 52, 5120; [4] Friščić, Jones Cryst. Growth Des., 2009, 9, 1621; [5] Katsenis et al., Nature Comm., 2015, 6:6662; [6] Karki et al., CrystEngComm., 2009, 11, 470; [7] Friščić et al., Nat. Chem., 2013, 5, 66; [8] Ban et al., Anal. Chem., 2017, 89, 13176; 